\title{
PERSPECTIVAS SOBRE A RELAÇÃO ENTRE DIREITO E MORALIDADE: BREVÍSSIMOS APONTAMENTOS*
}

\section{PERSPECTIVES ON THE RELATIONSHIP BETWEEN LAW AND MORAL: BRIEF SUMMARY}

Neimar Roberto de Souza e Silva**

Resumo: $O$ presente artigo versa sobre a relação entre direito e moral. Tem como objetivo discorrer, de forma breve e concisa, sobre o modo pelo qual as correntes jurídicas positivistas e não positivistas qualificam a relação entre aqueles campos normativos. Nesse diapasão, enquanto as teses positivistas sustentam a independência entre os campos moral e jurídico, ou seja, que a normatividade jurídica tem a sua validade assegurada em razão de critérios formais de validade e eficácia social, as teses não positivistas defendem ora uma relação de dependência, ora uma relação de complementaridade com o direito. $\mathrm{O}$ tema proposto constitui-se num dos principais e mais antigos problemas para a conceituação do direito. Remonta à antiguidade clássica e permanece atual na polêmica sobre os critérios de validade e legitimidade da norma jurídica.

Palavras-chave: Direito. Moral. Positivismo jurídico. Jusnaturalismo. Póspositivismo jurídico.

Abstract: This article focuses on the relationship between law and morality. It aims to discuss, briefly and concisely about the way in which the positivist and nonpositivist legal currents qualify the relationship between those regulatory fields. In this vein, while the positivist thesis support the independence of the moral and legal fields, ie, the legal normativity has its validity assured due to formal criteria of validity and social effectiveness, non-positivist theories argue sometimes a relationship of dependency, now a complementary relationship with the law. The theme is in one of the leading and oldest problems for the concept of law. Dating back to classical antiquity and remains present in the controversy over the criteria of validity and legitimacy of the rule of law.

Keywords: Right. Moral. Legal positivism. Natural law. Legal postpositivism.

\footnotetext{
* Uma versão modificada deste artigo foi publicada no livro "Estudos em Homenagem ao Professor Doutor José Rogério Moura de Almeida Filho", de coordenação de Cleyson de Moraes Mello, José Rogério Moura de Almeida Neto e Regina Pentagna Pentrillo.

** Mestre em Direito (Hermenêutica e Direitos Fundamentais), pela Universidade Presidente Antônio Carlos. Especialista em Direito Civil pela Escola Superior de Advocacia/OAB-RJ. Graduado em Gestão de Negócios Imobiliários pela USS - Universidade Severino Sombra. Professor Adjunto de Direito Civil, Filosofia do Direito e IED, da Faculdade de Direito de Valença, CESVA/FAA (Centro de Ensino Superior de Valença, da Fundação Dom André Arcoverde).
} 


\section{INTRODUÇÃO}

Se há um debate tão antigo quanto inconcluso para a Teoria do Direito, este é o que trata sobre a relação entre direito e moralidade. Embora o consenso sobre haver diferenças ontológicas consideráveis, podem ser percebidos como pertencentes a um gênero próximo, qual seja, conjunto de normas de conduta humana.

Pretende-se, neste artigo, um rápido esboço sobre como a jusfilosofia tem percebido a possibilidade (ou não) de interação ou interseção estre os aludidos campos normativos, limitando-se às perspectivas jusnaturalista e juspositivista, mas com uma breve passagem pelo pós-positivismo jurídico.

A pesquisa é bibliográfica, básica e pura, cujo objetivo precípuo é tão somente possibilitar ao acadêmico neófito um fácil e sucinto panorama da questão proposta.

\section{PERSPECTIVA JUSNATURALISTA}

A ideia de que o direito positivo possui alguma vinculação com a moral é característica essencial da tese não positivista. A relação direito-moral pode ser considerada de dependência ou de complementaridade. Assim, enquanto esta reconhece uma relativa independência do campo jurídico em relação ao campo moral, como ocorre nas teorias pós-positivistas, por exemplo, aquela sustenta que o direito se fundamenta na moral, como é o caso da teoria jusnaturalista.

O jusnaturalismo, como corrente do pensamento jurídico, prescreve que o direito positivo tem a sua validade condicionada a um ideal regulativo (a justiça), que se verifica sempre quando há sintonia entre o direito posto e aquele que o precede, o direito natural ${ }^{1}$.

\footnotetext{
${ }^{1} \mathrm{O}$ fundamento do direito natural sofreu variações históricas. Num primeiro momento fundava-se no cosmos; depois, na divindade, e, com o iluminismo, na razão humana (jusracionalismo).
} 
Entre os antigos gregos esta precedência pode ser constatada na tragédia Antígona, de Sófocles; em Platão ${ }^{2}$ e Aristóteles. O Estagirita, em sua obra Ética a Nicômaco, faz distinção entre nomikón díkaion (direito legal) e physikón díkaion (direito natural) em dois critérios: enquanto o primeiro tem eficácia restringida às comunidades políticas singulares em que é posto e prescreve ações que devam ser observadas nos termos de uma lei, o segundo possui eficácia universal, observada em qualquer lugar e prescreve ações cuja bondade é objetiva, ou seja, independente do juízo de valor que os sujeitos possam dela fazer (BOBBIO, 1995, p. 16-17).

Os romanos também faziam tal distinção. Com o desenvolvimento e a expansão comercial e militar de Roma, o direito posto pelas estatuições dos quirites ${ }^{3}$, passa a coexistir com um outro, baseado na naturalis ratio ${ }^{4}$, o jus gentium. No direito romano, o jurisconsulto Paulo qualificava o direito natural como universal, imutável e bom (bonum et aequum), em contraposição com o direito positivo, particular, mutável e útil (BOBBIO, 1995, p. 19).

No período medieval, a ideia de direito natural foi corrente. Abelardo, por exemplo, definiu jus positum como sendo o direito posto pelos homens e direito natural como aquele não é posto por esses, mas pela natureza ou por Deus. Outro pensador que merece destaque é Tomás de Aquino, que, em sua Summa Theologica, discorre sobre a existência de quatro tipos de lei: 1) a lex aeterna, que representa a vontade divina; 2) a lex divina, que representa a vontade divina positivada nas Sagradas Escrituras; 3) a lex naturalis, que revela a lex aeterna na natureza às criaturas racionais ${ }^{5}$; e 4 ) a lex humana, que deriva da obra do legislador (BOBBIO, 1995, p. 20).

Como resultado do humanismo, os períodos moderno e contemporâneo vão atribuir à razão o fundamento do direito natural. Em Grócio, por exemplo, caberia à justa razão conhecer se um ato seria moralmente torpe ou necessário, conforme a natureza humana ou divina. Mesmo Immanuel Kant, que separou as funções da moral (imperativo categórico) das do direito (imperativo hipotético), fundamentou os dois campos na razão prática (LACERDA, 2011, p. 17).

\footnotetext{
${ }^{2} \mathrm{~A}$ obra Timeu, por exemplo, trata da justiça natural, em contraponto à justiça dos homens, v.g.

${ }^{3}$ Cidadãos romanos.

${ }^{4}$ Razão natural, conceito presente na filosofia estoica.

5 Partecipatio legis aeternae in rationali creatura.
} 
Jeremy Bentham partilhou da tese de dependência do direito à moral, embora seu conceito de moral (utilitário) não afinasse com o de Kant (deôntico). Para ele o campo do direito estava contido no campo moral, e podia ser representado por um diagrama de círculos concêntricos. Ainda, entre os jusfilósofos mais contemporâneos, encontramos quem defenda o jusnaturalismo, como Rudolf Stammleer, Gustav Radbruch e John Finnis, por exemplo.

\section{PERSPECTIVA JUSPOSITIVISTA}

A doutrina do positivismo jurídico, embora tão antiga quanto ao do direito natural ${ }^{6}$, passou a suplantar a do jusnaturalismo na medida em que as sociedades, cada vez mais plurais e heterogêneas, não mais admitiam a imposição de um fundamento material arbitrário para o Direito, ou seja, a imposição de uma visão de mundo de um grupo de pessoas sobre outras. A ideia de justiça, concebida como um produto do mundo da cultura, não conferia a objetividade tão necessária a um Direito que se mostrasse eficiente em garantir segurança e estabilidade ao desenvolvimento daquela sociedade.

A tese positivista sustenta que não há conexão necessária entre direito, moral e política, embora reconheça a possibilidade de conteúdo extrajurídico, como valores morais, por exemplo, na norma jurídica. Para ela, o Direito deve ser axiologicamente neutro, não cabendo a consideração, portanto, do valor de justiça como critério de sua validade, como defendiam os jusnaturalistas. $O$ fundamento de sua validade deve ser formal.

Outro aspecto do juspositivismo é que, por não se vincular a standards morais, ele prescinde de uma teoria prescritiva, ocupada em dizer como deve ser o Direito, o que faz sentido, pois, ao prescrever o Direito corre-se o risco de se cair no campo da axiologia, o que soaria como uma incoerência, haja vista os postulados da neutralidade e da objetividade. Daí, o porquê de se limitar a uma teoria descritiva (a de dizer como o direito é).

\footnotetext{
6 Podemos citar como exemplo Protágoras (481-411 a.C.); Trasímaco (459-400 a.C.) e Carneades (214-129 a.C.), que compreendiam o direito como meramente uma convenção humana.
} 
Destarte, Por não caber ao jurista considerações de ordem zetética ao direito objetivo, limitando-se ele à verificação de critérios de validade e competência, o raciocínio próprio do positivismo jurídico é o lógico-dedutivo. 0 juiz deve dizer o direito com base na subsunção dos fatos à norma vigente, independentemente se seu conteúdo afronta a moralidade. Nas palavras de Kelsen:

\begin{abstract}
Uma norma jurídica não vale porque tem um determinado conteúdo, quer dizer, porque o seu conteúdo pode ser deduzido pela vida de um raciocínio lógico do de uma norma fundamental pressuposta, mas porque é criada por uma forma determinada - em última análise, por uma forma fixada por uma norma fundamental pressuposta. Por isso, e somente por isso, pertence ela à ordem jurídica cujas normas são criadas de conformidade com esta norma fundamental. Por isso, todo e qualquer conteúdo pode ser Direito. Não há qualquer conduta humana que, como tal, por força do seu conteúdo, esteja excluída de ser conteúdo de uma norma jurídica. A validade desta não pode ser negada pelo fato de o seu conteúdo contrariar o de uma outra norma que não pertença à ordem jurídica cuja norma fundamental é o fundamento de validade da norma em questão (KELSEN, 1999, p. 139).
\end{abstract}

\title{
4 PóS-POSITIVISMO E MORALIDADE
}

Destarte, alguns críticos do juspositivismo afirmam que este, ao dissociar a moralidade do direito, pode instrumentalizar, juridicamente, ideologias totalitárias e injustas, como já ocorreu em relação ao Estado Nazista, por exemplo. Citando Alyson Mascaro:

[...] o exacerbado positivismo do jurista rendeu críticas em momentos extremos. No Nazismo, quando as leis de Hitler eram aplicadas pelo simples fato de serem formalmente válidas, sem que o jurista tenha se sentido minimamente desconfortável com elas, a subsunção, como procedimento universal, revelava os limites éticos e sociais das normas jurídicas. (MASCARO, 2013, p. 186).

O problema da solução dos casos difíceis ${ }^{7}$ descortina outras fragilidades da teoria positivista, quais sejam: 1) a questão da integralidade do ordenamento jurídico no caso de ausência de regras claramente aplicáveis a um caso concreto; e 2) a questão da discricionariedade nas decisões judiciais.

A respeito do primeiro caso, famoso é o debate Hart - Dworkin, onde este último critica o pensamento do autor da obra The Concept of Law (HART, 1961), entre outras coisas, pelo fato deste conceber o direito enquanto regras reconhecidas

\footnotetext{
7 Aqui entendidos como aqueles onde não há uma lei ou um precedente pelo qual claramente se possa deduzir a decisão judicial.
} 
por sua origem, não explicando como princípios poderiam ser identificados mediante regras de reconhecimento, e, principalmente, o relevante papel que desempenham como normas que tornam possível a integridade do Direito.

Quanto à discricionariedade dos juízes, Kelsen entende a decisão jurídica como um ato de vontade, e, assim sendo, que não necessita de uma conclusão lógica derivada de certos argumentos, pois decisões são tomadas, e não deduzidas. Já, em Hart, a textura aberta do Direito forçosamente admite o juiz como criador do direito. Ambos os posicionamentos mereceram duras críticas dos autores póspositivistas, uma vez que entendem que os juízes devem julgar conforme o ordenamento jurídico preexistente, e, no caso de ausência de regras claras, com base nos princípios jurídicos vigentes no sistema. Desta forma, não há que se falar em poder discricionário dos juízes.

Por não darem conta do pluralismo e da complexidade da sociedade pósmoderna, alguns postulados do positivismo jurídico passaram a ser repensados. Propiciou-se, então, um espaço a teorias jurídicas que admitissem uma construção racional do direito, e, também, ética, no contexto do Estado Democrático de Direito. Vários jusfilósofos se empenharam na construção destas teorias ${ }^{8}$. É quando passamos a falar em uma tese pós-positivista do direito.

A bem da verdade, a definição do termo pós-positivismo não é unívoca. Todavia, aqui seguimos na esteira de Thomas Bustamante (2012, p. 167-168), considerando pós-positivismo como um conjunto de teorias jurídicas que: 1) estabelecem limites, em casos extremos, ao conteúdo do direito, por meio dos critérios formais ou institucionais utilizados pelo positivismo; 2) ditam uma relativa obrigação de que as decisões judiciais devem guardar um mínimo ético, reconhecendo-se um "umbral de injustiça" que o jus positum não deve ultrapassar; e 3) que, também, considerem o Direito como uma prática social argumentativa, e que

8 Aqui citamos alguns: Jürgen Habermas, que concebe a livre e crítica comunicação (ação comunicativa) como uma razão comunicativa, que supera o modelo racional do iluminismo. A noção de intersubjetividade recoloca a relevância do conteúdo ético no discurso jurídico, que deve ser fruto do consenso de uma comunidade; Ronald Dworkin, e seu ultra racionalismo, que nos traz a ideia de integridade do Direito e a importância da atitude interpretativa que permite ao juiz enxergar a melhor luz da norma jurídica; Robert Alexy, que, ao lado de Neil MacCormick, nos fornece uma teoria argumentativa para o direito, preocupada com a questão da correção das decisões judiciais. 
apenas não sejam descritivas (como as de Kelsen e de Hart), mas prescritiva, haja vista que sua realização (jurídica) deverá ser justificada por uma razão prática.

Desta forma, a tese jurídica pós-positivista não prescinde de certo grau de moralidade como fator de justificação do direito, pois este, em essência, "apresenta uma disposição à correção moral" (BUSTAMANTE, 2012, p. 168).

\section{CONSIDERAÇÕES FINAIS}

Sabemos sobre as semelhanças e diferenças entre os campos do direito e da moral. Como semelhanças, podemos apontar que ambos os campos são normativos, pois prescrevem regras de conduta que são fundadas em uma racionalidade prática. Como diferenças, temos em conta as características da heteronomia, da coercibilidade e da bilateralidade atributiva do direito, enquanto que na moral, respectivamente, percebemos a autonomia, a incoercibilidade e a unilateralidade de suas normas.

A questão que se colocou, todavia, é como as correntes positivistas e não positivistas do direito encaram a (possível) relação entre o mundo jurídico e a moralidade. A partir daí, apresentamos três abordagens distintas: 1) a dos positivistas $^{9}$; 2) a dos jusnaturalistas e 3) a dos pós-positivistas, como não positivistas.

Na primeira abordagem, direito e moral são realidades distintas, que, necessariamente, não se relacionam. Enquanto ciência, o direito deve ser axiologicamente neutro e objetivo. Uma norma jurídica não vale em razão de seu conteúdo, mas porque é criada por uma forma determinada de acordo com a norma fundamental.

Quanto às últimas duas abordagens, vimos que ambas admitem a relação entre direito e moral ${ }^{10}$. Entretanto, distanciam-se em como percebem a qualidade desta relação. Pela doutrina jusnaturalista, a validade da norma jurídica está condicionada a critérios materiais de correção moral. A moral, sendo um campo mais amplo, contém o direito. Os pós-positivistas compreendem a independência entre os

\footnotetext{
${ }^{9} \mathrm{O}$ termo "positivista" no sentido estrito, conforme as teorias de Kelsen, Hart, Raz, etc.

${ }^{10}$ Moral aqui sendo tomada em amplo sentido: teleológica (ética), deontológica ou discursiva.
} 
campos do direito e da moral e não assumem a existência de um direito natural, mas sustentam que o direito positivo possui uma carga moral (MACCORMICK, 2006) ou uma pretensão à correção (ALEXY, 2009) que o impede de ser extremamente injusto.

\section{REFERÊNCIAS}

ALEXY, Robert. Conceito e Validade do Direito. Trad. Gercélia Batista de Oliveira Mendes. São Paulo: Martins Fontes, 2009.

BOBBIO, Norberto. O Positivismo Jurídico. Lições de filosofia do Direito. Tradução: Márcio Pugliesi. São Paulo: Ícone, 1995.

BUSTAMANTE, Thomas da Rosa de. Teoria do Precedente Judicial. Justificação e aplicação de regras jurisprudenciais. São Paulo: Ed. Noeses, 2012.

KELSEN, Hans. Teoria Pura do Direito. Tradução: João Baptista Machado. São Paulo: Martins Fontes, 1999.

LACERDA, Bruno Amaro. Direito e Moralidade. In: LACERDA, Bruno Amaro; FERREIRA, Flávio Henrique Silva; FERES, Marcos Vinício Chein (org.). Instituições de Direito. Juiz de Fora: Ed. UFJF, 2011. p. 15-26.

MACCORMICK, Neil. Argumentação Jurídica e Teoria do Direito. Tradução: Waldéa Barcellos. São Paulo: Martins Fontes, 2006.

MASCARO, Alysson Leandro. Introdução ao Estudo do Direito. 4. ed. São Paulo: Atlas, 2013. 